\title{
Pathological study of a rare case of lipoblastomatosis with review of literature
}

\author{
Arathi $\mathrm{N}^{1}$ \\ ${ }^{1}$ Department of Pathology, SMV Medical College and Research Centre, Madagadipet, Pondicherry, India
}

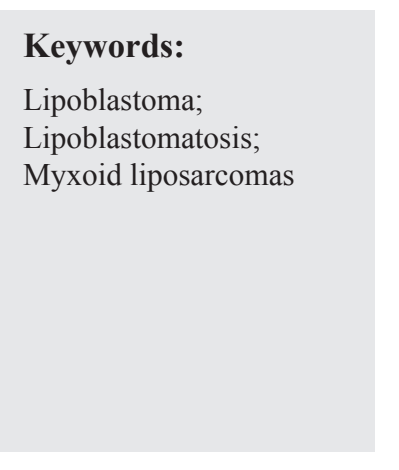

\begin{abstract}
Lipoblastomatosis refers to a rare benign tumour of fetal adipose tissue, commonly encountered in early childhood. It presents as a painless, slowly growing mass, usually in superficial soft tissues. Microscopy reveals a lobulated architecture with variable admixture of lipoblasts and mature adipocytes, along with myxoid areas showing spindle shaped cells. The behavior is benign, though recurrences can occur. We present a case of lipoblastomatosis of the right chest wall in a 20 year-old male patient, present since early childhood. The tumour measured $21 \times 13 \times 4 \mathrm{~cm}$; the cut section was grey white to tan. Microscopy revealed mature adipose tissue in most of the areas and an occasional lipoblast. Myxoid areas with spindle cells were seen. Adjacent muscle showed infiltration by the tumor. This case is presented for its rarity and for having had an opportunity to study the morphology of lipoblastomatosis several years after its onset in early childhood.
\end{abstract}

\section{INTRODUCTION}

Lipoblastoma and lipoblastomatosis represent circumscribed and diffuse types of benign tumours of adipose tissue, usually occurring in infants and young children. They are thought to arise from fetal/embryonic white fat. The extremities are commonly involved. Microscopically, lobularity is the characteristic feature; the lobules are composed of variable admixture of uni and multivacuolated lipoblasts, mature adipocytes and stellate/spindle cells in loose myxomatous areas. Plexiform vascular pattern may also be seen. The behavior is benign, though recurrence can occur, especially in the diffuse variant. The most important differential diagnosis is myxoid liposarcoma. Occurrence in older children and young adults can lead to a diagnostic dilemma.

\section{Correspondence:}

Dr. Arathi N, MD

Department of Pathology, SMV Medical College and Research Centre, Madagadipet, Pondicherry, India

Email: arathin10@gmail.com

\section{CASE REPORT}

A 20 year-old male patient presented with painless swelling on the right side of the chest wall, since early childhood. He was not sure of the exact age of onset. There had been a gradual increase in the size of the swelling. There was no prior history of biopsy or excision. He consulted a surgeon at this point of time because of difficulty in lifting the arm and approximating it to the lateral chest wall. On examination, a huge oval shaped smooth and firm swelling over the right lateral side of the chest was noted, measuring $22 \times 17 \mathrm{~cm}$, extending below the right axilla, from 3rd to 11th rib and anteroposteriorly from the outer border of the right scapula to just below the right nipple, occupying the entire lateral chest wall. The overlying skin was free and retractable. Clinically, a diagnosis of lipoma was considered. Peroperatively, the tumour was seen in the subcutaneous plane, adherent to chest wall muscles. Due to infiltrative nature of the lesion, wide excision was not possible. 


\section{Histopathological findings}

On gross examination, the mass was ovoid, measured $21 \times 13 \times 4 \mathrm{~cm}$. Capsule was not identified. External surface was smooth and shiny. Cut section was solid, grey white to tan and admixed with gelatinous areas. Necrosis was not seen. Microscopically, the tumor was partially encapsulated with lobular architecture. The lobules were separated by fibrous septae of varying thickness (fig.1).

Most of the lobules showed mature adipocytes with an occasional univacuolar lipoblast. Loose myxoid areas were also present, with a spindle cell population. The tumour showed rich vascularity (fig.1). Chicken wire pattern of blood vessels, hyperchromasia, multinucleation of the cell nucleus and mitotic figures were not seen. Infiltration of the adjacent skeletal muscle is evident at the periphery of the lesion (fig.2).

\section{DISCUSSION}

Lipoblastoma and lipoblastomatosis represent respectively circumscribed and diffuse variants of benign tumors of embryonal adipose (white) tissue, encountered in infancy and childhood. They can be considered as peculiar variants of lipoma and lipomatosis occurring in this age group. ${ }^{1}$ The term lipoblastomatosis was coined in 1958 by Vellios. ${ }^{2}$

Lipoblastomatosis is seen almost exclusively in childhood with majority of the cases presenting within 5 years of age. ${ }^{3-}$ ${ }^{5}$ They can also present as congenital tumours. ${ }^{3,5}$

Lipoblastomatosis occurring in adults is almost unknown. Silverman et al6 report a case in a 48 year-old male patient, which may be the first case of adult lipoblastoma. In our case though the patient consulted the surgeon at $20 \mathrm{yrs}$ of age, the history dates back to childhood.

Most of the series report a male predominance. ${ }^{3-5} \mathrm{~A}$ slight female predominance was noted in the study of 26 cases by Hicks. ${ }^{7}$ The tumours commonly present as slowly growing painless soft tissue mass.

Location wise these tumors usually occur in superficial soft tissues, especially in the extremities. Various other sites which have been described are neck, trunk, retroperitoneum, mediastinum and some rare areas like parapharyngeal space and lungs. ${ }^{3,5,7,8}$ In the unusual case of lipoblastoma in an adult, the tumour was located in the subcutis of the dorsum of the neck. ${ }^{6}$

Grossly the tumour is usually encapsulated and lobulated with most of them measuring less than $5 \mathrm{~cm}$. Lipoblastomatosis can have an incomplete capsule and show infiltration into surrounding tissue. Cut surface varies from yellow-tan to cream white; myxoid areas are commonly seen. The striking feature on histology is lobular arrangement, separated by

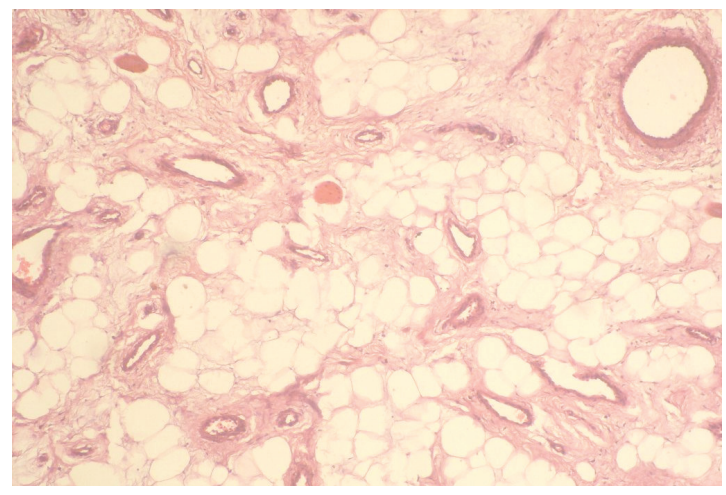

Figure 1: Lobular architecture of predominantly mature adipocytes along with rich vascularity (HE stain, X400).

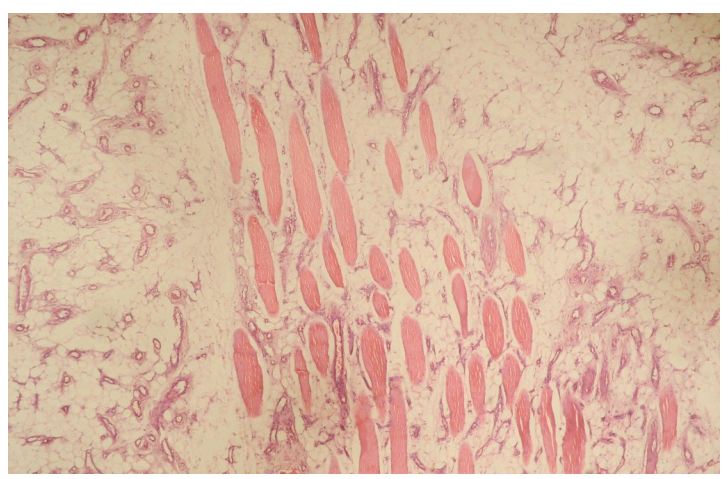

Figure 2: Peripheral margins of the tumor showing skeletal muscle infiltration (HE stain, X400).

fibrous tissue. The cell composition within the lobules varies, comprising of lipoblasts (uni and multivacuolar) and mature adipose tissue. Myxoid areas show spindle shaped cells which are more common in the periphery. Mitoses are generally not seen; if present, atypical mitoses are absent. ${ }^{3}$ Delicate, plexiform vascular pattern (chicken-wire) is seen in some cases.

The most important differential diagnosis is myxoid liposarcoma, both sharing some of the morphological features like lobularity, lipoblasts and plexiform vascular pattern. Lipoblastomatosis is a tumor of early childhood and almost unknown after adolescence while liposarcomas are extremely rare in this age. However, Schmookler and Enzinger ${ }^{9}$ have studied 17 cases of liposarcoma under 15 yrs of age; 13 of these cases were myxoid liposarcomas. Amongst these 13 cases, only one of them was younger than $10 \mathrm{yrs}$ (3 yrs of age). Lobularity was not seen while microcysts were noted in some cases. ${ }^{9}$

Atypical mitoses, pleomorphism and hyperchromasia favor liposarcoma.

Notwithstanding the various clinical and morphological features for differentiating these two entities, the diagnostic dilemma may persist in some cases. Cytogenetics is a 
valuable tool in such cases. $8 \mathrm{q}$ abnormalities are commonly reported in lipoblastomatosis while $\mathrm{t}(12 ; 16)(\mathrm{q} 13, \mathrm{p} 11)$ is detected in more than $90 \%$ of myxoid liposarcomas. ${ }^{7,10}$ In the possible first adult case of lipoblastomatosis reported by Silverman et al, the growth pattern, anatomic features and molecular data provided support for the diagnosis. ${ }^{6}$ In our case, though the patient presented at 20 yrs of age, the history dates back to very early childhood. Majority of the areas showed mature adipose tissue. Atypia, mitoses and pleomorphism were not seen. The characteristic lobularity was present. We could not undertake molecular study.

Ultra structural study reflects the variety of cells seen on light microscopy. Greco et al opine that lipoblastomatosis in all likelihood represents proliferation of mesenchymal cells which show various degrees of maturation towards white adipose tissue. $^{8}$

The behavior is benign; local recurrence can occur, especially in the diffuse variant and following an incomplete excision. $^{3-5}$ In some cases, further maturation into adult type of adipose tissue was noted in the recurrent tumour. ${ }^{4}$ Interestingly, one of the recurrent tumours described by Mentzel et al showed a more immature appearance, compared to the initial tumor. ${ }^{5}$

This case presented us with a rare opportunity to examine histologically a case of lipoblastomatosis in an adult, following its onset in early childhood. Though most of the areas were comprised of mature adipose tissue, myxoid areas were still noted. Till date our patient has not come for follow-up.

\section{CONCLUSION}

It is important to identify the rare lipoblastoma / lipoblastomatosis as benign tumour of fetal white adipose tissue, occurring during childhood and differentiate it from myxoid liposarcoma, taking into consideration the age, morphology and cytogenetics findings.

\section{REFERENCES}

1. Enzinger FM, Weiss SW editor. Soft tissue tumors. 3rd ed.MosbyYear Book Inc:USA.1995.pp556.

2. Vellios F, Baez JM, Shumacker HB. Lipoblastomatosis: A tumor of fetal fat different from hibernoma. Report of a case, with observations of the embryogenesis of human adipose tissue. Am J Pathol 1958;34:1149-59.

3. Chung EB, Enzinger FM. Benign Lipoblastomatosis- An analysis of 35 cases. Cancer 1973;32:482-92.

4. Collins $\mathrm{MH}$, Chatten J. Lipoblastoma / Lipoblastomatosis: A Clinicopathologic Study of 25 Tumors. Am J Surg Pathol 1997;21:1131-7.

5. Mentzel T, Calonje E, Fletcher CDM. Lipoblastoma and lipoblastomatosis: a clinicopathological study of 14 cases. Histopathology 1993;23:527-33
6. Silverman JS, Hamilton J, Tamsen A. Benign recurring Lipoblastoma in an adult versus well differentiated subcutaneous myxoid liposarcoma: clinicopathologic, immunohistochemical and molecular analysis of a unique case. Pathol Res Pract 1999;195:787-92.

7. Hicks J, Dilley A, Patel D, Barrish J, Zhu SH, Brandt M. Lipoblastoma and Lipoblastomatosis in Infancy and Childhood: Histopathologic, Ultrastructural and Cytogenetic Features. Ultrastructural Pathol 2001;25:321-33.

8. Greco MA, Garcia RL, Vuletin JC. Benign LipoblastomatosisUltrastructure and Histogenesis. Cancer 1980;45:511-5.

9. Schmookler BM, Enzinger FM. Liposarcoma Occurring in Children. An analysis of 17 cases and Review of Literature. Cancer 1983;52:567-74.

10. Chen Z, Coffin CM, Scott S et al. Evidence by spectral karyotyping that $8 \mathrm{q} 11.2$ is non-randomly involved in lipoblastoma. J Mol Diagn 2000;2:73-7. 